\title{
Chapter 6 \\ History of Mathematics, Mathematics Education, and the Liberal Arts
}

\author{
Michael N. Fried
}

\begin{abstract}
This paper considers how the history of mathematics, if it is taken seriously, can become a mode of thinking about mathematics and about one's own humanness. What I mean by the latter is that by studying the history of mathematics rather than simply using it as a tool—and that means attempting to understand it as an historian does - one becomes aware of how mathematics is something human beings do that therefore informs our human identity. In this way, the history of mathematics in mathematics education has the potential to make us fuller human beings, which is at the heart of the educational tradition known as the "liberal arts." By considering the nature of the liberal arts, we may understand better the meaning of the history of mathematics in mathematics education and, indeed, the meaning of mathematics education tout court.
\end{abstract}

Keywords History of mathematics · Humanistic mathematics · Liberal arts Whiggism

This paper concerns the history of mathematics and mathematics education. I should say from the start that I will not display results from empirical research showing how the history of mathematics is good for this or that. This is not because I belittle such research. Not at all. However, much of that research treats the history of mathematics as a tool, to use the phrase Jankvist (2009) has popularized. Again, I have no objection to questions about tools and utility. Indeed, the last part of my lecture concerning the liberal arts is in some way a matter of profound utility. Nevertheless, emphasizing the use of the history of mathematics, as I pointed out in my 2001 paper on the subject (Fried 2001), draws us away from the meaning of the history of mathematics in mathematics education. It is that - the meaning of the history of mathematics in mathematics education as something to study rather than to use-that I wish to elaborate here.

M. N. Fried ( $\square)$

Ben Gurion University of the Negev, Beersheba, Israel

e-mail: mfried@bgu.ac.il

(C) The Author(s) 2018

G. Kaiser et al. (eds.), Invited Lectures from the 13th International Congress

on Mathematical Education, ICME-13 Monographs,

https://doi.org/10.1007/978-3-319-72170-5_6 
The paper will comprise four parts. By way of introduction, I will say a few words about D. E. Smith, whose importance both in the field of mathematics education - not the least because of his involvement in ICMI, the organization behind this conference-and in the history of mathematics is undeniable. Next, I will discuss the nature of history and its character as a discipline. Following that, I will make the point that a non-historical tendency enters mathematics teaching when history is viewed as something to be used only, and that that leads to a kind of dilemma for the teacher who has a serious interest in history. This third section will end, however, by suggesting that that very dilemma can provide us with an opportunity to review what we really mean by mathematics education or, rather, by the mathematically educated person. Finally, I will turn briefly to the old idea of the liberal arts. Taking the term artes liberales literally, these are the arts of a "free human being," or, better, of a fully human being. Thinking about the liberal arts in connection to the history of mathematics, I will claim, has the potential of bringing us back to a mathematics education aiming to make our students more fully human. And with that we may obtain insight into the meaning both of the history of mathematics in mathematics education and mathematics education itself.

\subsection{By Way of Introduction: David Eugene Smith}

Despite its apparent distance from mainstream empirical research in mathematics education, the subject of my paper is, I believe, appropriate for the ICME community. For one, there are several other sessions in the conference centered on historical ideas. But, more than that, the history of mathematics was a central preoccupation of David Eugene Smith (1860-1944), whose remarks in L'Enseignement Mathématique in 1905 set into motion the creation of ICMI in the first place. For this reason alone it is worth saying a few words about Smith. But thinking about Smith and his views also brings us directly into the set of ideas I wish to develop in this paper.

As most of you probably know, the 1905 article in L'Enseignement Mathématique was a response to an inquiry (published in the same volume of the journal) concerning the reforms necessary for the teaching of mathematics. Smith was only one respondent among others including such luminaries as Gino Loria and Emile Borel. It was Smith's view, though, that what was urgently needed was an international organization dedicated to questions on mathematics teaching. And, partly in response to Smith's proposal, the ICMI was created three years later. But more pertinent to my subject in this paper, in that same short piece in 1905, Smith also took the opportunity to express his views about the importance of the history of mathematics. He said that, regarding the training of mathematics teachers, besides knowing integral and differential calculus, the teacher, “....also ought to know, in a precise way, the historical development of subjects being taught, why were they were taught, how were they presented in different places" (Smith 1905, p. 470, my translation). 
Smith had already stated a similar position more than once in his earlier work, The Teaching of Elementary Mathematics (Smith 1902). I would add too, that, like me, Smith is critical in this work about the motive of utility in mathematics education. He tells us that there are two main motives for teaching arithmetic:

....arithmetic, like other subjects is taught either (1) for its utility, or (2) for its culture. Under the former is included the general "bread-and-butter value" of the subject and its applications; under the latter, its training in logic, its bearing upon ethical, religious and philosophical thought. (p. 20)

He says that the utility motive favored by the "mechanical teacher" (as he puts it, together with another expression, the "machine teacher") is overrated and that it is the cultural motive that should be developed. On the other hand, by a "cultural motive" he seems mostly to mean a motive towards thoughtful and reflective learning. Thus, just a few lines after the sentence just quoted, he emphasizes that "[arithmetic] has cultural value because, if rightly taught, it trains one to think closely and logically and accurately" (p. 20) - which one might say is a more profound utility and more important for human life than the mechanical operations necessary for the day-to-day work of a storekeeper.

It is remarkable that D. E. Smith does not set the history of mathematics as an integral part of the "cultural motive." The history of mathematics would seem to be at the very heart of culture. For, whatever else it may mean, "culture" surely embraces at its core the doings and productions of human beings in a certain place and time. What makes this even more astonishing is that Smith was extraordinarily learned in the history of mathematics and wrote voluminously on the subject; he also amassed a collection of thousands of manuscripts and books related to the history of mathematics that was legendary (see Swetz and Katz 2011; Donoghue 1998). And in the book On Teaching Elementary Mathematics, which I have been referring to, Smith's arguments are, in a very pointed and explicit way, based on historical evidence. Almost from start to finish, Smith the historian of mathematics is at work. So how do we explain this seeming paradox?

The answer, I believe, can be discerned in the way that Smith argues that the history of mathematics should have a place in mathematics education. For he earnestly believes that, as I have already stated, and provides two justifications (Smith 1902). The first is based on the "parallelism argument," that is, that the development of an individual parallels the development of mathematics itself. As Smith himself suggests, this is an old argument. To be sure, it has had a long history before Smith, as one discovers in Schubring's thorough and deep works on the parallelism idea (e.g., Schubring 1978). It was also the driving argument for Toeplitz, whose "genetic approach" was laid out in 1926 (see Fried and Jahnke 2015), and it is still a potent argument for incorporating the history of mathematics in mathematics teaching (see Furinghetti and Radford 2008; Thomaidis and Tzanakis 2007). Here is how Smith states the position:

...the child learns somewhat as the world learns. This does not mean that the child must go through all of the stages of mathematical history-an extreme of the "culture-epoch" theory; but what has bothered the world usually bothers the child, and the way in which the 
world has overcome its difficulties is suggestive of the way in which the child may overcome similar ones in his own development. (pp. 42-43)

Smith's second argument is that history of mathematics serves as a kind of filter allowing one to see clearly what has proven important and fruitful and what turned out to be effete and not worth pursuing. In Smith's words:

...the history of the subject [he is speaking specifically about the history of arithmetic, but the argument is general] gives us a point of view from which we can see with clear vision the relative importance of the various subjects, what is obsolete in the science, and what the future is likely to demand. (p. 43)

Despite Smith's immense factual knowledge of the history of mathematics and his wide reading and scholarship, these arguments, I claim, presuppose a certain view of mathematics in which mathematics, at bottom, is an unhistorical subject; that is, it is one unaffected in any essential way by time and place or what we might call culture. This can be seen in Smith (1921) presidential address to Mathematics Association of America (Smith 1921). He called it "Religio Mathematici," the "religion of a mathematician," after Sir Thomas Browne's Religio Medici, which was Browne's spiritual testament of his own identity as a doctor. So Smith's "Religio Mathematici" is Smith's credo concerning the nature of mathematics and, from it, one can infer with little trouble his credo concerning the history of mathematics. Among other things, he writes:

One thing that mathematics early imparts, unless hindered from so doing, is the idea that here, at last, is an immortality that is seemingly tangible,-the immortality of a mathematical law...The laws of the Medes and Persians, unchangeable though they were thought to be, have all perished; the canons that bound Egyptian activities for thousands of years exist only in the ancient records, preserved in our museums of antiquity...But in the midst of all these changes it has ever been true, it is true today, it shall be true in all the future of this earth, and it is equally true throughout the universe whether in the algebra of Flatland or in that of the space in which we live, that $(a+b)^{2}=a^{2}+2 a b+b^{2}$. (p. 341)

Mathematics does not change in this view, though it may be not be revealed all at once. Its history, therefore, cannot be a history of change and development; despite missteps here and there, it is rather the progressive unveiling of the immortal truth - true everywhere "throughout the universe."

Thus, it is not surprising that, for Smith, history should reveal a kind of natural direction of ideas and that its course should be consistent with that of an individual's intellectual development. It is not marked by the arbitrariness or idiosyncrasy one finds in artistic creation and thus cannot be "cultural" in the way one expects the history of art or literature to be. Thus Smith contrasts mathematics with the laws of Persia and the canons of Egypt: If mathematics has a historical aspect, it is a different kind of history from that of Egypt or Persia.

Moreover, the usefulness of the history of mathematics in mathematics education, its capacity to be a tool, comes from its unchanging character. Unlike the norms of Egypt or Rome, it will always be relevant, and its history will open our eyes and provide a measure of the importance of things according to an immortal, unchanging scale. It is for this reason that, as Smith says in the passage quoted 
above, "the history of the subject gives us a point of view from which we can see with clear vision the relative importance of the various subjects, what is obsolete in the science, and what the future is likely to demand."

These comments about Smith serve to bring out several points, all of which are central to any considerations regarding the history of mathematics and mathematics education. First, how one conceives the history of mathematics is not a direct result of one's learnedness; Smith's positions were not the result of his not knowing enough about dates, thinkers, and texts. Second, the role one assigns to the history of mathematics in mathematics education is inseparable from one's conception of the nature of mathematics. Third, in a similar way, how one conceives a cultural motive in mathematics teaching is connected to how one conceives mathematics; in particular, it is connected to its historical or non-historical character. Fourth, the non-historical character of the history of mathematics is in fact what allows it to be a tool, whether for guiding the teaching of individual students or for guiding the design of a curriculum.

To these I would like to add the converse of the last point, namely, that when one asks the history of mathematics to be a tool in mathematics teaching, one forces the history of mathematics to be non-historical. I will have to justify that claim, although it can be said immediately that to the extent that history is either what has been or the disciplined account of what has been, the student of history is something other than the user of a tool; therefore, treating history as a tool is ab initio contrary to history. However, before one even begins to talk about what it is to be non-historical, one should have a sense of the historical. So having encountered Smith's Religio Mathematici let us look at what might be called Religio Historici.

\subsubsection{Religio Historici}

Of course the word religion ought to be uttered with a smile. There is no single dogma to which all historians ascribe when it comes to their craft. Still, one can say that, if not quite a religion, there is at least a historical orientation: a set of preoccupations recognizable by almost all historians despite considerable disagreement as to how one should pursue those preoccupations.

The question of sources is one such preoccupation, and in the case of intellectual history, of which the history of mathematics is an example, these are chiefly original texts. The centrality of original texts as a way of incorporating the history of mathematics in mathematics education was, accordingly, emphasized by Laubenbacher et al. (1994), for example. This has remained central in historical work, though its objective character has been challenged, for example, in Carr's What Is History? whose first chapter concerns what he called "the cult of facts" (Carr 1967, p. 9). Carr's position was that history cannot be removed from the historian's perspective on the past. This does not mean that the study of original texts is outdated. Far from it. Objections by Carr and many others keep alive the question of the meaning of sources. 
Having a perspective on the past is connected to what is arguably the most important preoccupation of history, namely, the past itself or, rather, the relationship between the past and present. No doubt it is the past that jumps to one's mind when one hears the word history. However, a view of the past and history are not synonymous: It matters very much exactly how one considers the past.

Michael Oakeshott (1901-1990), in his various writings on history, has pressed the point that the "'historical past' denotes a distinguishable mode of the past" (Oakeshott 1999, p. 9). In his first and most famous book, Experience and Its Modes (1933), he says that in fact there are "certain pasts [that] may be dismissed at once as alien to history" (Oakeshott 1933, p. 102). There is, he says, among others, a remembered past or autobiographical past, a fancied past, and a practical past. It is the last of these that he considers most opposed to the historical past, and, accordingly, the one that brings out the nature of the historical past.

The practical past is a past whose entire mode of being is that of something involved with the present; it is derived and inspired by the present, important if important to the present, pursued if it is significant for our present concerns or even if it allows a way to escape them. As Oakeshott puts it:

\footnotetext{
Wherever the past is merely that which preceded the present, that from which the present has grown, wherever the significance of the past lies in the fact that it has been influential in deciding the present and future fortunes of man, wherever the present is sought in the past, and wherever the past is regarded as merely a refuge from the present - the past involved is a practical, and not an historical past. (Oakeshott 1933, p. 103)
}

Our ordinary human day-to-day lives are so much directed to the present it is difficult to think of the past in any other way and perhaps impossible to engage in thinking of the past in a way that we utterly forget the present. Yet the historical past, the object of historical inquiry, involves, as Oakeshott says elsewhere, "a redirection" of this kind of activity "inherent in a human life" (Oakeshott 1999, p. 127). The past may be like the present, in fact, in that it must be in some way like the present if it is to be understood at all; however, the activity of history involves the attempt, even if it is ultimately doomed to failure, to see the past as other than the present, to see, as he says, “... the past as past, and with each moment of the past in so far as it is unlike any other moment" (Oakeshott 1933, p. 106).

The insidious side of Oakeshott's practical past is that it presents itself as historical. This is less so, for example, in the case of a fancied past or legends of yore: Serious people rarely take a Disney world of knights and unicorns as the real thing. But a past viewed from the perspective of the present is not always questioned. It was for this reason that Herbert Butterfield (1900-1979) wrote his famous book, The Whig Interpretation of History (Butterfield 1931/1951), just two years earlier than the work of Oakeshott that we have been referring to. It was a book about historians-Butterfield refers to it in the preface, with a smile no doubt, as a book about "the psychology of historians" (p. vi) — and it is presumably addressed to historians. As for the term, "Whig history," he says: 
What is discussed is the tendency in many historians to write on the side of protestants and Whigs, to praise revolutions provided they have been successful, to emphasise certain principles of progress in the past and to produce a story which is the ratification if not the glorification of the present. (p. v)

And Butterfield, like Oakeshott, points to the essential character of a historical account in trying to grasp the otherness of the past in the attempt to see the past for itself:

...the chief aim of the historian is the elucidation of the unlikenesses between past and present and his chief function is to act in this way as the mediator between other generations and our own. It is not for him to stress and magnify the similarities between one age and another, and he is riding after a whole flock of misapprehensions if he goes to hunt for the present in the past. (p. 10)

\subsection{History of Mathematics and Mathematics Education}

This kind unhistorical history is particularly tempting in the history of mathematics, precisely because of the "religio mathematici" that Smith espoused. For if one takes mathematics to be essentially unchanging and immortal, then at bottom there is no difference between past and present. Therefore, with that in mind, one may freely translate the mathematics of the past into a modern idiom and use the present unabashedly as a guide to the past. The Whig perspective would, in that light, be completely unobjectionable and, undoubtedly, enlightening. Thus, in his well-known polemical article in 1975, Unguru declared that "Whig history, a dead horse nowadays - one would like to believe - in most branches of history, is alive and thriving in the history of mathematics, where its dangers are no less real than in the more traditional types of intellectual history" (Unguru 1975, p. 86).

Well aware of these difficulties, Grattan-Guinness (2004a, b) suggested two approaches to treating the mathematics of the past, history and heritage. These are distinguished by their guiding questions: History asks, "What happened?" or "Why did $N$ happen?"; heritage asks "How did we get here?" The answer, Grattan-Guinness playfully points out, is more often than not via "the royal road to me." Grattan-Guinness is perfectly willing to say that "heritage resembles Whig history, the seemingly inevitable success of the actual victors, with predecessors assessed primarily in terms of similarities with the dominant position" (Grattan-Guinness 2004b, p. 171).

There is no doubt Grattan-Guinness's history/heritage dichotomy can be a useful tool for analyzing how mathematics of the past is treated; however, it does not adequately explain what it is we truly learn from heritage as opposed to history, and it does not bring out explicitly enough how these different approaches to the past are in fact different views of the past itself and place one in a different relation to the past. For they are truly different relations, even incompatible ones, as I think even Grattan-Guinness would have to admit. For this reason, in my book on Apollonius 
with Sabetai Unguru, we spoke about going through a historical door or a mathematical door (Fried and Unguru 2001, p. 404ff). Each door leads into a very different world: "The mathematical and the historical approaches are antagonistic. Whoever breaks and enters typically returns from his escapades with other spoils than the peaceful and courteous caller" (p. 406).

It should not be thought that the accusation of Whiggism or of an adherence to some other form of non-historical history is an accusation of being unlearned. It is not about not knowing enough history. As I have already mentioned, Smith was immensely learned. Clifford Truesdell (1919-2000) who was, among other things, the editor of Euler's collected works, was also a tremendously learned man, yet he was decidedly Whiggish in his approach to history, or at least happy to view the past as "practical past." Thus, he could write, for example, that

one of the main functions [the history of mathematical science] should fulfill is to help scientists understand some aspects of specific areas of mathematics about which they still don't fully know. What's more important, it helps them too. By satisfying their natural curiosity, typically present in everybody towards his or her own forefathers, it helps them indeed to get acquainted with their ancestors in spirit. As a consequence, they become able to put their efforts into perspective and, in the end, also able to give those efforts a more complete meaning. (in Giusti 2003, p. 21)

It is clear from his writings that Truesdell felt truly that the figures of the past were, as Littlewood famously said, merely "fellows of another college" (Hardy 1992, p. 81). I emphasize the learnedness of Smith and Truesdell only to bring out that the meaning of history is to be found in how one approaches the past: It is not a direct function of how many names and dates one can recite. This is crucial not only for one who desires insight into the history of mathematics, but more importantly for those of us who are teachers who desire to use the history of mathematics to inform our teaching.

The two cases are not symmetrical. Historians of mathematics and those who wish simply to learn from history will gain by engaging with mathematical texts and thoughts from the past while giving cognizance to the meaning of history, the meaning of the past, and the meaning of thinking about the past. And that, as I have argued, requires actively avoiding the present and treating it as an unproblematic guide to the past. History, in fact, is not quite history without that.

But mathematics teachers as mathematics teachers have other unavoidable concerns. They have a curriculum to follow; they may have national examinations or some other kinds of large-scale examination for which they are obliged to prepare their students. A brave and bold teacher might decide, despite everything, to put aside such external constraints in order to treat the history of mathematics in a spirit of religio historici; however, that spirit, with its demand that the present be suspended, cannot be an imperative for mathematics teachers. It is not just that it is unnecessary: It conflicts with other imperatives. For the mathematics that mathematics teachers teach - the kind of mathematics laid out in the Common Core, for example - is crucial for the present and has more than historical import. No one can deny the kinds of approaches, techniques, and ideas that belong to mathematics of the present are genuinely useful in the sciences, engineering, and industry and that 
they are genuinely interesting, enlightening, and often beautiful. A teacher placing an emphasis on such mathematics cannot be condemned.

The external demands made on teachers and, perhaps, their own legitimate commitment to teaching the mathematics of the present - the mathematics needed in applications and in modern science-makes it easier to put history aside than put modern mathematics aside. But if there are mathematics teachers who nevertheless aim to bring history of mathematics into their teaching, they must, because of those external demands, economize by making history fit their other concerns. They must show its relevance to subjects already being taught or, alternatively, show its relevance to general mathematical thinking: what Smith called "culture." They must make history of mathematics useful. But in doing so, they are led almost ineluctably into precisely the "practical history" of Oakeshott or "Whiggist history" of Butterfield, which I described above: the past in the service of the present.

It is easy to find examples written by educators equally ignorant of mathematics education research and the history of mathematics, but such examples prove very little. On the other hand, it is not difficult to find papers where this is not the case. I have a paper in my files, for instance, called, "The history of mathematics as a pedagogical tool: Teaching the integral of the secant via Mercator's projection" (Haverhals and Roscoe 2010). I choose to highlight it because (1) it presents a good way of introducing the Mercator projection as it is used in geography and presents a pleasant way of teaching the integral of the secant function and showing its relevance and (2) its authors show an awareness of some of the literature being written in mathematics education research on history of mathematics (for example, Janvist 2009; Siu 2007; Ernest 1988) and a willingness to confront it. Yet, when it comes down to it, true to their title, history is not so much a subject to study as it is a tool to use and, as such, can be freely adapted for educational use. Thus, referring to the difficulties of original texts whose importance I have already mentioned, they say, "...student difficulty in confronting historical text can be alleviated by careful and thoughtful presentation that is at once historically accurate while educationally streamlined toward an intended goal, in this case, an understanding of the integral of the secant" (p. 354).

The authors have clear priorities. The priorities are not unreasonable. Haverhals and Roscoe are interested in teaching a subject, in this case the integral of the secant function, and have found a good example with historical color: It is an example that has the potential of holding the interest of the students and making their authors' task something more than an empty exercise. I emphasize this to make it clear that the authors' priorities are indeed priorities: They are to a great extent given in advance by commitments to a standard calculus curriculum. So if historical material is used, its use must be subordinated under the demands of such a modern curriculum. If the authors were to ignore the modern notion of the integral and the functional way of thinking, they could be more historical but undoubtedly less successful in achieving the teaching goals of their mathematics lessons. In effect, they are compelled to adopt a Whiggist perspective. For this reason, when I began thinking about the question of incorporating the history of mathematics in 
mathematics teaching, I stated the deliberations of a mathematics teacher interested in the history of mathematics as a kind of dilemma:

...if one is a mathematics educator, one must choose: either (1) remain true to one's commitment to modern mathematics and modern techniques and risk being Whiggish, i.e., unhistorical in one's approach, or, at best, trivializing history, or (2) take a genuinely historical approach to the history of mathematics and risk spending time on things irrelevant to the mathematics one has to teach. (Fried 2001, pp. 397-398)

At the time I wrote that, I thought the dilemma was inescapable and, much to my dismay, damning to almost any serious attempt to bring the history of mathematics into mathematics teaching. This was not for lack of good historical material. Writers such as Victor Katz, Frank Swetz, and the late John Fauvel, among others, work from the IREM team in France, and the many papers presented at the HPM-ESU conferences have all supplied plentiful historical sources and discussions for thinking about the history of mathematics. But as long as mathematics education was committed to the modern mathematical ideas necessary for the needs of modern life, as so many of the general documents pertaining to mathematics education declare - as, for example, when the NCTM's Principles and Standards for School Mathematics describes itself to be "the first set of rigorous, college, and career readiness standards for the 21st century" (NCTM 2016) - any use of history, I thought then, would have to be marked by the selection, abridgment, and organization of material for the modern ends that Butterfield underlined as the hallmark of Whig history.

But mathematics education both as an enterprise and as the focus of mathematics education research is not so rigidly defined: Its commitments are not written in stone. This means that, in principle at least, rather than asking how to adapt the history of mathematics to a fixed mathematics education with a predetermined set of commitments, one can ask how mathematics education might be conceived so that the history of mathematics plays an essential part in it, that is, where it is something to be studied and thought about. In this regard, the dilemma I set out in 2001 should be viewed more as a challenge to redefine mathematics education informed by the history of mathematics than as a criticism of past efforts.

It would be unfair to say there has been until now no thought in this direction. A survey of many of the ideas can be found in Fried (2014), and many of these predate 2001. It is beyond the scope of this lecture to summarize the work of all the scholars described there, but, as a sample, I would certainly mention the work of Radford, whose ideas on the semiotic and cultural core of mathematics education (for example, Radford 2015) have inspired many of us here; there is Jankvist and Kjeldsen's (2011) work within the context of the Danish competencies framework, which includes the history of mathematics; and then we have Jahnke's hermeneutic approach (e.g., Jahnke 2000), in which mathematics learners are conceived as interpreters, so that the reading of historical texts becomes a way of exploring one's own mathematical identity. My only contribution has been to sharpen the question to which these are possible answers. 


\subsection{The Liberal Arts}

To characterize concretely mathematics education in which history forms an integral part, I could mention, for example, the centrality of original texts. I referred to this above in connection to the work of Laubenbacher et al. (1994). Or I could speak about some of the proposals connected to Jahnke's work cited above. But, since time is short, I would rather end with a much more general picture: one inspired by a concomitant history of the history of mathematics, namely, the history of education itself. What I have in mind specifically are the liberal arts.

It is true that the liberal arts come specifically from the history of education in the West, but, as I said, my intention is to use them as an image, a general picture, not a promotion of the West or a denigration of any other tradition. This tradition, however, is still very much a part of students' lives. Students who receive a BA or MA degree have, by name at least, received degrees in the liberal arts, for those are precisely the arts intended by Bachelor of Arts and Master of Arts. Even more, the MA, Magister Artium, is the qualification to teach the liberal arts. And here I say as an aside that whether or not it is right to think of history in terms of memory, it is certainly true that it treats the kind of forgetfulness that occurs when original meanings are lost in the light of modern transformations. Students who write the letters BA and MA after their names are oblivious, more often than not, to the traditions buried under their degrees.

The tradition of the liberal arts is a long one, although its systematization into an educational scheme became most clearly articulated in late antiquity. The usual scheme involved seven liberal arts. Of these, three were, in a sense, connected to language. These formed the trivium, the "three ways," of grammar: the nature of letters, words, sentences - rhetoric, or the artful use of words - and logic - the formation of arguments. The other four arts, contrary to the modern tendency to set mathematics and science apart from the liberal arts, were explicitly mathematical. These mathematical arts formed the quadrivium, the "four ways": the arts of arithmetic, geometry, astronomy, and music. I should mention that there were other schemes for the liberal arts; for example, in Varro's lost treatise, The Nine Books of Disciplines, written during the first century BCE, there were, besides these seven arts, two more: architecture and medicine (see Wagner 1986, p. 15ff). Nevertheless, in time the trivium and quadrivium became more or less the canonized scheme (see Fig. 6.1).

It is important to understand that the arts were thought of as a system-particularly the mathematical arts: a system no less unified than a system of the world. Thus, Proclus (412-485 CE), recalling the Pythagorean tradition, tells us that the quadrivium was structured so that arithmetic and geometry corresponded to the basic division between multitude and magnitude, with arithmetic being about numbers in themselves, pure multitudes, and geometry being about magnitudes at rest, figures that do not move. Music was derivative from arithmetic, being the study of numbers taken relatively to other numbers, such as the harmonic divisions of a string, while astronomy was geometry in motion (see Fig. 6.2). 


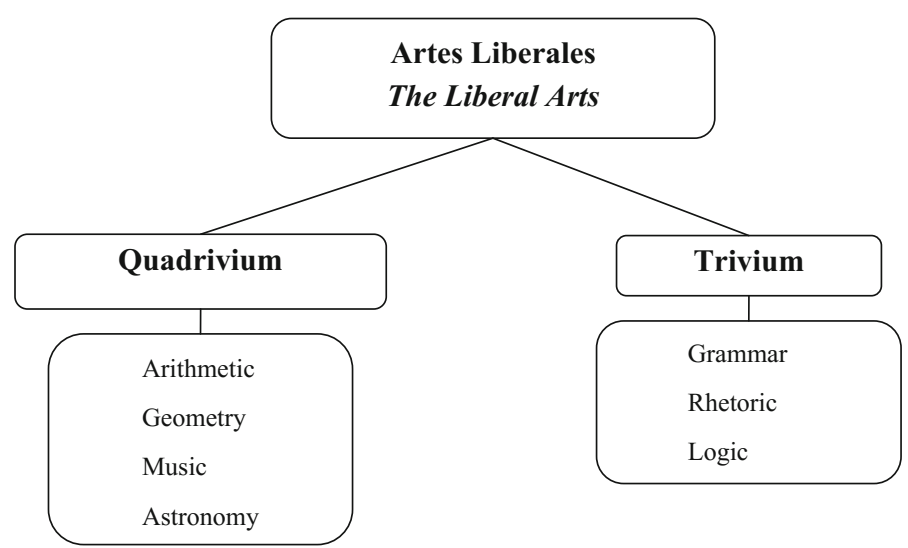

Fig. 6.1 The liberal arts

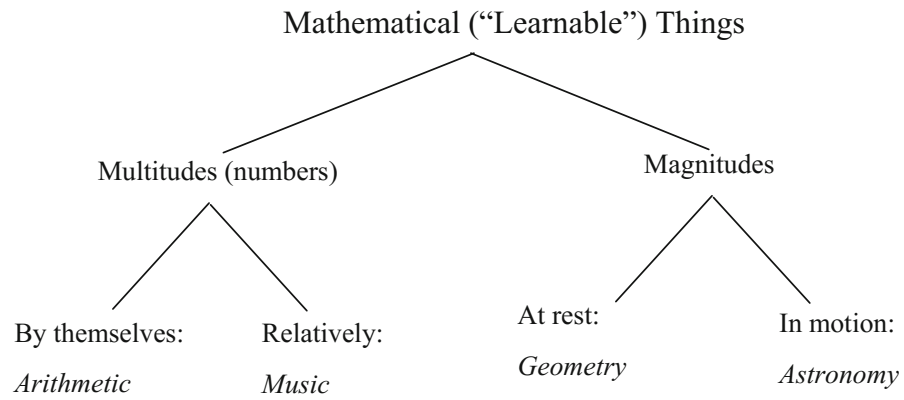

Fig. 6.2 The Pythagorean division of mathematics

One can disagree with the organizational principle; however, what is important is that there was an organizational principle at all, an attempt to present education as a reflection of a whole.

That the learnable things, the mathemata, reflected the whole universe was almost certainly the result of Pythagorean doctrines. Whether the Pythagoreans had much use for the arts in the trivium is not nearly as clear, even though, surely, later Pythagoreans, such as Nichomachus of Gerasa, from whom we know much about Pythagorean teachings, were well versed in grammar, rhetoric, and logic. They could hardly express themselves so well without rigorous training in the trivium. ${ }^{1}$

\footnotetext{
${ }^{1}$ There was among especially the Church Fathers, Augustine and Jerome, for example, a certain tension between the rigor of this training and its connection to classical oratory on the one hand and unadorned inner spirituality on the other. One can detect an echo here of a similar tension today in mathematics education, namely, that between rigorous training in mathematical techniques and procedures and intuitive and original thinking.
} 
But there is another sense in which the liberal arts reflected a whole, where the full complement of the arts was essential. Indeed, in Martianus Capella's early fifth century CE allegory, The Marriage of Philology and Mercury, the seven liberal arts, seven sisters, bestow the gifts that sanctify the marriage of the maiden Philology and Mercury, gifts which make the pair one. In general, our sources are largely "encyclopedias" written around this time, works by Boethius, Cassiodorus, and Isadore of Seville. This was the time when the Roman Empire was breaking down, and the need for inner coherence rooted in the tradition under threat was felt acutely.

The word encyclopedia is significant. It is a combination of two Greek words, engkuklios and paideia; the first, coming from kuklos, a circle, means what happens over and over, regularly, or common to all. The second may be translated variously as culture, upbringing, or, education, so that engkuklios paideia is something like the education common to all. The word paideia is truly the difficult - and therefore most important - word here. Jaeger (1945) required three thick volumes to explain it. But one can say that (1) paideia was rooted in the literature and thought of one's tradition - here the translation "culture" is apt and (2) it was meant to be carried throughout life, so that (3) it was very much an expression of being a human in the fullest sense of the word, thus the Latin translation of paideia came to be, revealingly enough, humanitas (see Marrou 1982, p. 218).

It is not by chance of course that encyclopedias, with their connection to the classical idea of paideia, should be the place where the liberal arts were discussed. For the study of the liberal arts was inseparable from the idea of paideia, even identified with it. They were called liberal arts because, like paideia, they were directed towards human beings who are not slaves but who are free to pursue a life allowing them to be fully what they are as human beings. In the history of paideia, this was particularly true in the post-Socratic period. Thus Jaeger (1945) writes:

\footnotetext{
...it is Socrates' idea of the aim of life which marks the decisive point in the history of paideia. It threw a new light on the purpose and duty of all education. Education is not the cultivation of certain abilities; it is not the communication of certain branches of knowledge.... The real essence of education is that it enables men [in gender-insensitive language of 1945] to reach the true aim of their lives.... This effort cannot be restricted to the few years of what is called higher education. Either it takes a whole lifetime to reach its aim, or its aim can never be reached. Therefore the concept of paideia is essentially altered; and education, in the Socratic sense, becomes the effort to form one's life along lines which are philosophically understood, and to direct it so as to fulfill the intellectual and moral definition of man. In this sense, man was born for paideia. It is his only real possession. (Jaeger 1945, Vol. II, pp. 69-70, emphasis original)
}

At this point, one might complain that although I have been looking back at a chapter in the history of education, I seem to have departed from history as suchand it is the history of mathematics in mathematics education that is my topic. The objection is actually more acute than one might think, for while the seven liberal arts were not fixed in the past, as a pointed out earlier, history was never considered one of them. On the other hand, today the liberal arts considered central to the 
"humanities" and have become the locus of historical study, while mathematics, traditionally always part of the liberal arts, has nearly become excluded from them.

The new place of history as the prime liberal art is partly the result of a change in the understanding of history, at least since the time of 17th-18th century figures such as Giambattista Vico (1668-1744) and certainly since Hegel. The idea that we ourselves may be historically constituted, that history might represent for human life the clearest kind of truth, has driven the modern idea of history. It has also made the aim of the liberal arts - the exploration and fulfillment of our human life as free, thinking beings - in some quarters the aim of history as well. Thus Collingwood could say:

[The historian's knowledge] is not either knowledge of the past and therefore not knowledge of the present, or else knowledge of the present and therefore not knowledge of the past; it is knowledge of the past in the present, the self-knowledge of the historian's own mind as the present revival and reliving of past experiences. (Collingwood 1993, p. 175; see also Fried 2007)

The place of history as the central liberal art was certainly challenged by, for example, Thomas Huxley in the second half of the 19th century. Huxley doggedly made the case that science should be at the heart of education; indeed, one of his essays, which makes this point, is called "A Liberal Education; and Where to Find It" (1868, in Huxley 1899, pp. 76-110). Calls to increase science education today, with their tacit belittlement of the humanities, I believe, echo Huxley's well-meant sentiments. Moreover, to return to Smith, with whom I began, it may be said that his use of the word culture without history stems from the same sentiment that impelled Huxley to speak about liberal education with science at the center, more paleontology than history, to use one of Huxley's own points.

But I think it is fair to say that culture, for us, not only in general and in history but also in mathematics education itself, is impossible to untie from history and a view of ourselves as historical beings. Mathematics education in this light can look back to the liberal arts in which mathematics was central and in which their place in defining a full human life can be informed by the historical sense of a human life. The problem therefore of the history of mathematics and mathematics education in this way becomes a challenge to rethink mathematics education in terms of the liberal arts and the attempt to see ourselves more clearly and more deeply as the beings that created mathematics. If the history of mathematics is taken as a tool, then it must be taken in the way the liberal arts were tools: arts to be used but also a source on which we reflect about mathematics and ourselves.

\subsection{Concluding Words}

History, as we said, has become central to the liberal arts, while mathematics has become excluded. The history of mathematics is one way of restoring mathematics as a liberal art. Conversely, thinking of mathematics as a liberal art opens the way to 
the history of mathematics becoming an essential part of mathematics education. It allows mathematics to assume a place in a human life that is taken as an integral whole in a world that is taken as an integral whole. As in all history (as Collingwood has said) and in all the liberal arts, mathematics education, in this light, becomes a way of reflecting on ourselves.

Reflecting about ourselves and our human capabilities is humanism. It must be understood, however, that the liberal arts, which can be taken as another term for humanism, are not a dogma. In the same way, history and tradition, while being formative, are not binding. As one of my own teachers, Eva Brann, liked to point out, in thinking about tradition, one must remember that the Latin word tradere means both "to pass on" but also "to betray" (Brann 1979, p. 64). Searching for a whole, either of the world or of tradition or of traditions, a search that ultimately cannot be consummated, brings us thus to an openness to our own incompleteness - and therefore, to our own potentialities. We look back at our own foundations in history and by recognizing that truly, using Gadamer's (2006) language, we look beyond our own horizon.

\section{References}

Brann, E. T. H. (1979). Paradoxes of education in a republic. Chicago: Chicago University Press. Butterfield, H. (1931/1951). The whig interpretation of history. New York: Charles Scribner's Sons.

Carr, E. H. (1967). What is history? London: Penguin Books.

Collingwood, R. G. (1993). The idea of history. Oxford: Oxford University Press.

Donoghue, E. F. (1998). In search of mathematical treasures: David Eugene Smith and George Arthur Plimpton. Historia Mathematica, 25, 359-365.

Ernest, P. (1988). The impact of beliefs on the teaching of mathematics. Paper presented at ICME VI, Budapest, Hungary.

Fried, M. N. (2001). Can mathematics education and history of mathematics coexist? Science \& Education, 10, 391-408.

Fried, M. N. (2007). Didactics and history of mathematics: Knowledge and self-knowledge. Educational Studies in Mathematics, 66, 203-223.

Fried, M. N. (2014). History of mathematics and mathematics education. In M. Matthews (Ed.), History, philosophy and science teaching handbook (Vol. 1, pp. 669-705). New York: Springer.

Fried, M. N., \& Jahnke, H. N. (2015). Otto Toeplitz's 1927 paper on the genetic method in the teaching of mathematics. Science in Context, 28(2), 285-295.

Fried, M. N. \& Unguru, S. (2001). Apollonius of Perga's Conica: Text, context, subtext. Leiden, The Netherlands: Brill Academic Publishers

Furinghetti, F., \& Radford, L. (2008). Contrasts and oblique connections between historical conceptual developments and classroom learning in mathematics. In L. English (Ed.), Handbook of international research in mathematics education (2nd ed., pp. 626-655). Mawah, NJ: Lawrence Erlbaum. 
Gadamer, H. G. (2006). Truth and method (2nd ed., J. Weinsheimer \& D. G. Marshall, Trans.). New York: Continuum.

Grattan-Guinness, I. (2004a). History or heritage? An important distinction in mathematics and for mathematics education. The American Mathematical Monthly, 111(1), 1-12.

Grattan-Guinness, I. (2004b). The mathematics of the past: Distinguishing its history from our heritage. Historia Mathematica, 31, 163-185.

Giusti, E. (2003). Clifford Truesdell (1919-2000), historian of mathematics. Journal of Elasticity, $70,15-22$.

Hardy, G. H. (1992). A mathematician's apology. Cambridge: Cambridge University Press.

Haverhals, N., \& Roscoe, M. (2010). The history of mathematics as a pedagogical tool: Teaching the integral of the secant via Mercator's projection. The Montana Mathematics Enthusiast, 7 (2\&3), 339-368.

Huxley, T. H. (1899). Science and education. London: Macmillan and Co., Limited.

Jaeger, W. (1945) Paidea: The ideals of Greek culture (Vol 3, G. Highet, Trans.). New York: Oxford University Press.

Jahnke, H. N. (2000). The use of original sources in the mathematics classroom. In J. Fauvel \& J. van Maanen (Eds.), History in mathematics education: The ICMI study (pp. 291-328). Dordrecht: Kluwer Academic Publishers.

Jankvist, U. T. (2009) A characterization of the "whys" and "hows" of using history in mathematics education. Educational Studies in Mathematics, 71(3), 235-261.

Jankvist, U. T., \& Kjeldsen, T. H. (2011). New avenues for history in mathematics education: Mathematical competencies and anchoring. Science \& Education, 20, 831-862.

Laubenbacher, R., Pengelley, D., \& Siddoway, M. (1994). Recovering motivation in mathematics. In Teaching with original sources, UME trends 6. Available at the website: http://www.math. nmsu.edu/ history/ume.html. Accessed December 31, 2015.

Marrou, H. I. (1982). A history of education in antiquity (G. Lamb, Trans.). Madison, WI: University of Wisconsin Press.

NCTM. (2016). Principles and standards for school mathematics. At the website: http://www. nctm.org/Standards-and-Positions/Principles-and-Standards/. Accessed January 15, 2016.

Oakeshott, M. (1933). Experience and its modes. Cambridge: At the University Press.

Oakeshott, M. (1999). On history and other essays. Indianapolis, IN: Liberty Fund, Inc.

Radford, L. (2015). Early algebraic thinking: Epistemological, semiotic, and developmental issues. In S. J. Cho (Ed.), The Proceedings of the 12th International Congress on Mathematical Education (pp. 209-227). Cham: Springer.

Schubring, G. (1978). Das genetische Prinzip in der Mathematik-Didaktik [The genetic principle in mathematics education]. Stuttgart: Klett.

Smith, D. E. (1902). The teaching of elementary mathematics. New York: The Macmillan Company.

Smith, D. E. (1905). Réformes à accomplir dans l'enseignement des mathématiques: Opinion de M. Dav.-Eug. Smith. L'Enseignement Mathématique, 7, 469-471.

Smith, D. E. (1921). Religio Mathematici: Presidential address delivered before the Mathematical Association of America, September 7, 1921. The American Mathematical Monthly, 38(10), 339-349.

Siu, M. K. (2007). No, I don't use history of mathematics in my class. Why? In F. Furinghetti, S. Kaijser, \& C. Tzanakis (Eds.), Proceedings HPM2004 \& ESU4 (pp. 268-277). Uppsala: Uppsala Universitet.

Swetz, F. J., \& Katz, V. J. (2011). Mathematical treasures-The David Eugene Smith collection. MAA: Convergence. Available at the website: http://www.maa.org/press/periodicals/ convergence/mathematical-treasures-the-david-eugene-smith-collection. Accessed December $11,2015$. 
Thomaidis, Y., \& Tzanakis, C. (2007). The notion of historical 'parallelism' revisited: Historical evolution and students' conceptions of the order relation on the number line. Educational Studies in Mathematics, 66(2), 165-183.

Unguru, S. (1975). On the need to rewrite the history of Geek mathematics. Archive for History of Exact Sciences, 15, 67-114

Wagner, D. L. (1986). The seven liberal arts in the middle ages. Bloomington: Indiana University Press.

Open Access This chapter is licensed under the terms of the Creative Commons Attribution 4.0 International License (http://creativecommons.org/licenses/by/4.0/), which permits use, sharing, adaptation, distribution and reproduction in any medium or format, as long as you give appropriate credit to the original author(s) and the source, provide a link to the Creative Commons license and indicate if changes were made.

The images or other third party material in this chapter are included in the chapter's Creative Commons license, unless indicated otherwise in a credit line to the material. If material is not included in the chapter's Creative Commons license and your intended use is not permitted by statutory regulation or exceeds the permitted use, you will need to obtain permission directly from the copyright holder. 